\title{
Type I interferon (IFN)-inducible Absent in Melanoma 2 proteins in neuroinflammation: implications for Alzheimer's disease
}

\author{
Divaker Choubey (D)
}

\begin{abstract}
Cumulative evidence indicates that activation of innate immune responses in the central nervous system (CNS) induces the expression of type 1 interferons (T1 IFNs), a family of cytokines. The T1 IFNs (IFN- $\alpha / \beta)$, through activation of the JAK/STAT-signaling in microglia, astrocytes, and neurons, induce the expression of IFN-inducible proteins, which mediate the pro- and anti-inflammatory functions of IFNs. Accordingly, T1 IFN-inducible Absent in Melanoma 2 proteins (murine Aim2 and human AIM2) negatively regulate the expression of TI IFNs and, upon sensing higher levels of cytosolic DNA, assemble the Aim2/AIM2 inflammasome, resulting in activation of caspase-1, pyroptosis, and the secretion of pro-inflammatory cytokines (e.g., IL-1 $\beta$ and IL-18). Of interest, studies have indicated a role for the Aim2/AIM2 proteins in neuroinflammation and neurodegenerative diseases, including Alzheimer's disease (AD). The ability of Aim2/AIM2 proteins to exert pro- and anti-inflammatory effects in CNS may depend upon age, sex hormones, cell-types, and the expression of species-specific negative regulators of the Aim2/AIM2 inflammasome. Therefore, we discuss the role of Aim2/AIM2 proteins in the development of AD. An improved understanding of the role of Absent in Melanoma 2 proteins in AD could identify new approaches to treat patients.
\end{abstract}

Keywords: Type I IFNs, Alzheimer's disease, Neuroinflammation, AIM2 proteins

\section{Introduction}

In the central nervous system (CNS), most cell-types, including microglia and astrocytes, can produce type 1 interferons (T1 IFNs) [1, 2], a family of cytokines [1]. The T1 IFNs signal via the heterodimeric IFN- $\alpha / \beta$ receptor (IFNAR). Binding of T1 IFNs with the receptor activates the JAK/STAT-signaling pathway leading to transcriptional activation of the IFN-stimulated genes (ISGs) [1]. These genes encode for the proteins that mediate the pro- and anti-inflammatory functions of the T1 IFNs [2, 3]. T1 IFN response in the CNS may arise due to certain bacterial or viral infections $[4,5]$. Alternatively, traumatic brain injury (TBI) and neurodegeneration can also activate T1 IFN response [6-11]. Accordingly, a recent study reported expression of T1 IFN-inducible Absent in

Correspondence: Divaker.choubey@uc.edu

Department of Environmental Health, University of Cincinnati, 160 Panzeca Way, P. O. Box 670056, Cincinnati, OH 45267, USA
Melanoma 2 (Aim2) protein in the murine astrocytes and microglia [12].

Depending on the neurodegenerative disease state, T1 IFNs can be protective or deleterious [2]. For example, in multiple sclerosis (MS), a neuroinflammatory diseases, the T1 IFNs are thought to exert an anti-inflammatory effect through induction of the anti-inflammatory cytokine IL10 [13] and suppression of pro-inflammatory cytokine IL-1 $\beta$ production [14]. Consequently, the IFN- $\beta$ is a first-line therapy for certain MS patients. The therapy limits infiltration of lymphocytes into the brain and decreases relapse rate in MS patients $[2,15]$. However, a transgenic overexpression of the IFN- $\alpha$ gene in the brains of mice resulted in neuroinflammation and the development of a neurodegenerative disease $[16,17]$. Correspondingly, the IFN- $\beta$ levels are increased with age in individuals and an administration of anti-IFNAR1 antibodies in individuals inhibited the age-dependent cognitive decline [18]. 
Generation of the IFNAR1-null [19] or IFN- $\beta^{-/-}$mice [20] improved our overall understanding with respect to the role of T1 IFNs and the T1 IFN-signaling in neurodegenerative diseases. Surprisingly, the mice that were deficient in the Ifnb gene (encoding for IFN- $\beta$ ) exhibited a loss of the dopaminergic neurons, development of Lewy bodies and Parkinson's-like disease [20]. Of interest, the animal models of AD exhibited an increase in the expression of T1 IFNs and activation of the T1 IFN response in the CNS $[21,22]$. Accordingly, the $\mathrm{APP}_{\mathrm{SWE}} / \mathrm{PS}_{\triangle \mathrm{Eg}} \mathrm{AD}$ mice that were deficient in the IFN- $\alpha$ receptor gene (Ifnar1) exhibited a reduced pathology and an altered microglial phenotype [11]. Similarly, a study using a mouse model of Alzheimer's disease (5XFAD) indicated an inflammasome-independent role of T1 IFN-inducible Aim2 protein in the suppression of pro-inflammatory cytokines in the $\mathrm{Aim}^{-1-}$.(B6.Sv129); 5XFAD mice [23].

Type 1 (T1) interferonopathies are characterized by the constitutive production of T1 IFNs and activation of T1 IFN response (increase in the expression of ISGs) in cells [24-26]. The T1 interferonopathies usually involve mutation in genes that regulate the T1 IFN response $[25,26]$. Interestingly, certain types of $\mathrm{T} 1$ interferonopathies, including the Aicardi-Goutieres syndrome (AGS), are associated with activation of microglia in the CNS, resulting in chronic neuroinflammation [26, 27]. Further, chronic neuroinflammation is associated with many aging-associated neurodegenerative diseases (including Alzheimer's disease, Parkinson's disease, multiple sclerosis, and ataxia telangiectasia) in individuals and animal models of the diseases [28-30].

Accumulating evidence indicates that an inflammasome activation in glial and neuronal cells modulates neuroinflammation [31, 32]. The inflammasome is a cytosolic protein complex that contains multiple copies of a danger-sensing receptor (e.g., Aim2), pro-caspase1 , and an adaptor protein ASC (apoptotic speck containing protein with a CARD) [33]. Activation of an inflammasome in glial and neuronal cells results in caspase- 1 activation, pyroptotic cell death, and the release of pro-inflammatory cytokines, such as IL-1 $\beta$ and IL-18 [32, 34]. Activation of inflammasomes plays a pathogenic role in neurologic diseases such as multiple sclerosis, traumatic brain injury, and Alzheimer's disease $[31,32,35]$.

Development of aging-associated Alzheimer's disease (AD) is characterized by synaptic loss and neuronal death, which results in cognitive decline, dementia, and loss of motor functions with time [36-38]. Deposition of extracellular beta-amyloid $(A \beta)$ plaques and neurofibrillary tangles of the hyperphosphorylated microtubule-binding protein tau in the CNS is thought to play a role in the development and progression of aging-associated AD [36,
38]. However, it remains an open question whether an increase in the production of pro-inflammatory (such as IL-6 and IL-1 $\beta$ ) [39] that are produced by activation of an inflammasome in the CNS or anti-inflammatory (such as IL-10) $[40,41]$ cytokines contributes to the main defects in the clearance of the $\mathrm{A} \beta$ plaques in $\mathrm{AD}$ patients.

Cumulative evidence indicates a role for the T1 IFNsignaling in the development and progression of $\mathrm{AD}$ $[11,21-23,42]$. However, the role of IFN-inducible proteins, which mediate the pro- and anti-inflammatory activities of T1 IFNs in the CNS, remains unknown. Interestingly, studies using animal models have indicated a role for T1 IFN-inducible Aim2 protein in neuroinflammation and neurodegenerative diseases, including $\mathrm{AD}[12,23,43-48]$. Because the ability of Aim2/AIM2 proteins to exert pro- and anti-inflammatory effects in the CNS may depend upon the genetic background, age, sex hormones, cell-type, and speciesspecific expression of the negative regulators of the Aim2/ AIM2 inflammasome [49-52], here we discuss the role of these proteins in the development of neurodegenerative diseases.

\section{Interferon-inducible Absent in Melanoma 2 proteins}

The T1 IFN-inducible PYHIN-protein family includes the structurally related Aim2/AIM2 proteins that are encoded by the AIM2-like receptor (ALR)-family genes (ALR genes) [53-55]. The family includes the murine genes (including the Aim2 and Ifi202) and human genes (including the AIM2, IFI16, and POP3). Notably, the murine Aim2 and human AIM2 protein sequences are conserved between the mouse and humans. Most proteins in the family contain the $\mathrm{N}$-terminal Pyrin signaling domain (PYD) and the C-terminal DNA-binding HIN domain [53]. The murine-specific p202 [53] and human-specific IFI16- $\beta$ [56] proteins lack the PYDsignaling domain. Further, the human-specific POP3 protein lacks the DNA-binding HIN domain. The HIN domain can bind double-stranded DNA in sequenceindependent manner [53]. Interestingly, the p202 protein through the HIN domain interacted with the Aim2 protein and inhibited the activity of the Aim2 inflammasome [57]. Similarly, the T1 IFN-induced levels of the IFI16- $\beta$ and POP3 protein inhibited the activity of the AIM2 inflammasome [56, 58]. Basal (and T1 IFNinduced) expression of Aim 2 and p202 proteins may depend on the mouse strain and sex (see below) [49, 51, 52]. Further, basal expression of the Aim $2 /$ AIM 2 proteins is detectable in glial cells and astrocytes [12].

Bone marrow-derived macrophages from $\mathrm{Aim}^{-/} \mathrm{fe}-$ male mice on the mixed (B6.Sv129) [50] or pure C57BL/ 6 (B6) [51] genetic background expressed higher basal levels of the IFN- $\beta$ and activated the T1 IFN response. 
Further, Aim2-deficient mice on mixed genetic background exhibited inflammation and adipogenesis in white adipose tissue with age, leading to obesity and insulin resistance [59]. Notably, Aim2-deficiency in the B6.Sv129 and B6 mice resulted in an increase in the expression of the IFN-inducible p202 protein [50, 51, 59]. Because the basal expression of the p202 protein (a negative regulator of the Aim2 inflammasome) is much higher in the B6.Sv129 mouse strain than the B6 strain [60], studies using the $A i m 2^{-1-}$.(B6.Sv129) mice are not very informative with respect to the precise role of the Aim2 protein in the development of neuroinflammation and neurodegenerative diseases.

\section{Age-dependent expression of Aim2/AIM2 genes}

Analysis of the AIM2 gene expression in peripheral blood mononuclear cells (PBMCs) from vascular patients ( $n=77$, age $22-82$ years) revealed a significant positive association with age [61]. Notably, the analysis did not find a difference in AIM2 expression between patients with advanced atherosclerosis and other vascular diseases. Similarly, human normal lung fibroblasts (WI-38) in culture, upon aging, exhibited a measurable increase in the levels of the AIM2 protein [62]. However, a study [63], which analyzed AIM2 gene expression in PBMCs from healthy young ( $n=16$; age $20-39$ years) and elderly ( $n=18 ; 60-84$ years) individuals without any treatment or after in vitro stimulation of cells with poly(dA:dT), an AIM2 ligand, noted that the stimulation of cells from elderly individuals resulted in reduced expression of the AIM2 gene and pro-inflammatory cytokines than the young donors [63]. Because development of certain neurodegenerative diseases, such as $\mathrm{AD}$, is associated with aging and vascular dysfunction [64], it remains to be seen whether the expression of AIM2 gene and the functions of the AIM2 protein in the CNS decrease with the age.

\section{A male bias in the expression of Aim2/AIM2 genes} In purified splenic $\mathrm{B}$ cells $\left(\mathrm{B} 220^{+}\right)$and total sleenocytes from the B6, New Zealand black (NZB) and B6.Nba2 congenic males, as compared with age-matched females, the basal levels of the Aim2 mRNA and protein were significantly higher [49]. Further, treatment of the murine WT276 breast cancer cell line, which expresses the androgen receptor (AR), with dihydroxy-testosterone (DHT) measurably increased the steady-state levels of the Aim 2 mRNA and protein [49]. Similarly, expression of the AIM2 gene in PBMCs from males $(n=62)$ was higher than females $(n=38)$ [61]. Additionally, AIM2 mRNA levels in naïve macrophages were higher in SLE men $(n=6)$ than women $(n=9)$ [65]. Considering the above observations, it is conceivable that the basal expression of the Aim2 and AIM2 genes in microglia and astrocytes is regulated by the sex hormones in a cell-type dependent manner. Further, expression of the p202 protein [66] and IFI16 protein [67], the negative regulators of the Aim2 and AIM2 inflammasome, is regulated by the sex hormones. Because epidemiological studies suggest that lower androgen levels in elderly men are a risk factor to develop $\mathrm{AD}$ [68], studies are needed to investigate whether age-dependent decrease in the androgen levels in men is associated with reduced levels of the AIM2 protein and its functions in the CNS. Additionally, whether a reduced expression of AIM2 protein in women is associated with a female bias in the development of AD.

\section{Cytosolic DNA sensing: Aim2/AIM2 proteins in innate immune responses}

Lower levels of cytosolic DNA are sensed by cyclic GMP-AMP synthase (cGAS) in macrophages/microglia [51, 52, 69]. Upon sensing the cytosolic DNA, macrophages activate the STING-dependent IFN-stimulatory DNA pathway (ISD; also referred to as the cGASSTING-TBK1-IRF3 pathway) for the IFN- $\beta$ expression and activation of the T1 IFN response [70, 71], which upregulates the expression of Aim2/AIM2 genes [49, 61] and interleukin-10 (IL-10) [14]. However, higher levels of the cytosolic DNA are sensed by T1 IFN-inducible murine Aim2 and human AIM2 proteins in macrophages and the sensing activates the Aim2/AIM2 inflammasome and caspase-1 [69]. The activated caspase-1 proteolytically cleaves pro-IL-1ß (p31), pro-IL-18 (p24), and gasdermin $\mathrm{D}$, which leads to pyroptosis, a highly inflammatory cell death, and inflammation [72]. Notably, the activated gasdermin D in macrophages also limited activation of the T1 IFN responses [73]. These observations are consistent with a role for activation of the ISD pathway by lower levels of the cytosolic DNA to potentiate the activation of the Aim2/AIM2 inflammasome (through stimulation of the Aim2/AIM2 gene expression) in macrophages/microglia. In turn, activation of the Aim2/AIM2 inflammasome by higher levels of the cytosolic DNA in macrophages negatively regulates the ISD pathway to suppress T1 IFN response. Therefore, a mutual regulation between activation of ISD pathway and inflammasome pathway in the CNS may be critical to maintain a homeostasis (Fig. 1).

\section{The negative regulation of type I IFN response by Aim2/AIM2 proteins}

Immune cells (spleenocytes, macrophages, and dendritic cells) from Aim2-deficient male or female mice expressed higher basal levels of the IFN- $\beta$ mRNA and activated the T1 IFN response as compared with the age- and sexmatched wild-type B6 mice [50, 51]. Further, macrophages and DCs from the B6 female mice, when stimulated 


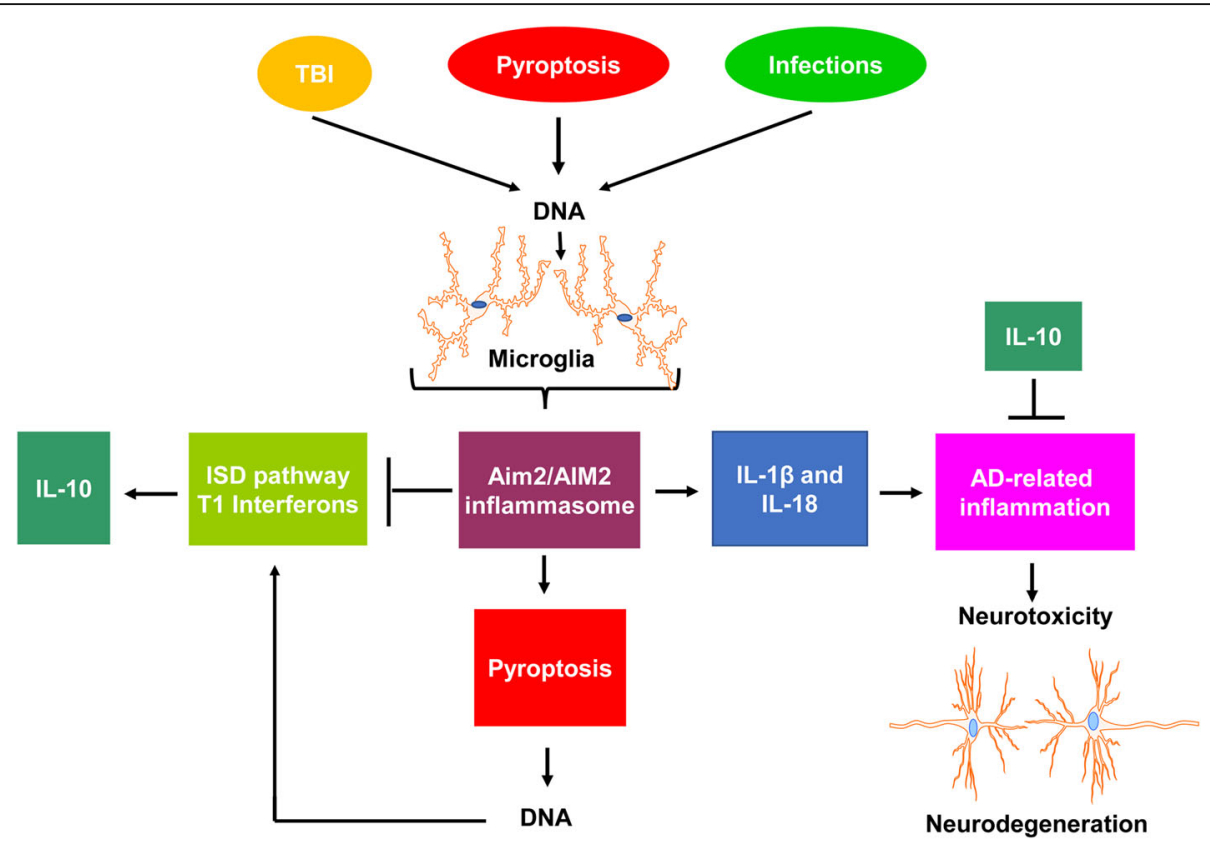

Fig. 1 Aim2 protein-mediated modulation of AD-related inflammation. Mouse microglia express detectable basal levels of Aim2 protein. Detection of low levels of cytosolic DNA, released in the brain due to traumatic brain injury (TBI), pyroptosis (caused by activation of inflammasomes), and brain infections, by cGAS activates the IFN-stimulatory DNA (ISD) pathway and the T1 IFN response, resulting in upregulation of the Aim2 gene expression and anti-inflammatory cytokine IL-10. The IL-10 suppresses neuroinflammation. Detection of increased levels of cytosolic DNA by macrophages/microglia activates the Aim2 inflammasome, resulting in the production of pro-inflammatory cytokines (IL-1 $\beta$ and IL-18) and cell death by pyroptosis. The activation of the Aim2 inflammasome and pyroptosis contributes to AD-related inflammation and associated neurotoxicity, resulting in neurodegeneration. Cell death by pyroptosis inhibits the ISD pathway and the production of IL-10

in vitro with DNA, activated the Aim2 inflammasome activity and inhibited activation of ISD pathway by caspase1-mediated pyroptotic cell death [73]. However, in vitro stimulation of macrophages from the NZB female mice, which express higher basal levels of the p202 protein than the B6 mice [74], resulted in an inhibition of Aim2 inflammasome activity as compared with sex-matched B6 mice [57]. Additionally, Aim 2 protein sequestered the T1 IFNinducible IFI205 protein and inhibited the IFI205mediated induction of IFN- $\beta$ through activation of ISD pathway [75]. Further, Aim2 protein also potentiated the Trex1-mediated suppression of T1 IFN response in macrophages through mechanisms dependent upon the cGas and Sting proteins [75]. Together, these observations suggest that Aim2 protein negatively regulates the T1 IFN response in inflammasome-dependent and -independent manner. Further, the Aim2 inflammasome-dependent pro-inflammatory response depends on the genetic background of the mice and their sex (Fig. 2).

Constitutive expression of the POP3 protein, a negative regulator of the AIM2 inflammasome [58], in murine macrophages "primed" macrophages, resulting in a significant increase in the production of the IFN- $\beta$ upon sensing of the cytosolic DNA [58]. Accordingly, a knockdown of the AIM2 protein expression in human normal lung fibroblasts (WI-38) activated the T1 IFN response and upregulated the expression of the IFN-inducible IFI16 protein [62], an activator of the ISD pathway [76]. Further, an increase in the expression of IFI16 protein [77] or its IFI16- $\beta$ isoform [56], which contains two HIN domains, sequestered the cytoplasmic DNA and inhibited activation of the AIM2 inflammasome [56, 77]. Considering the above observations, further work is needed to investigate the role of AIM2 protein in the negative regulation of T1 IFN response.

\section{Aim2 protein expression in the CNS and neuroinflammation}

An extensive expression analysis of T1 IFN-inducible cytosolic DNA sensors in highly purified primary astrocytes and microglia indicated that both cell-types express mRNAs encoding for the PYHIN-family proteins, including the Aim2 protein [12]. Treatment of microglia with IFN- $\beta$ upregulated the expression of certain cytosolic DNA sensors, including the Aim2 gene. Interestingly, in a murine model of chronic neurodegeneration, the expression of Aim 2 gene was upregulated in vivo in a T1 IFN-dependent fashion [12]. Further, acute CNS infection by $S$. aureus in mice resulted in the production of IL-1 $\beta$ and other inflammatory 


\section{Aim2 in AD-related inflammation \& neurodegeneration}

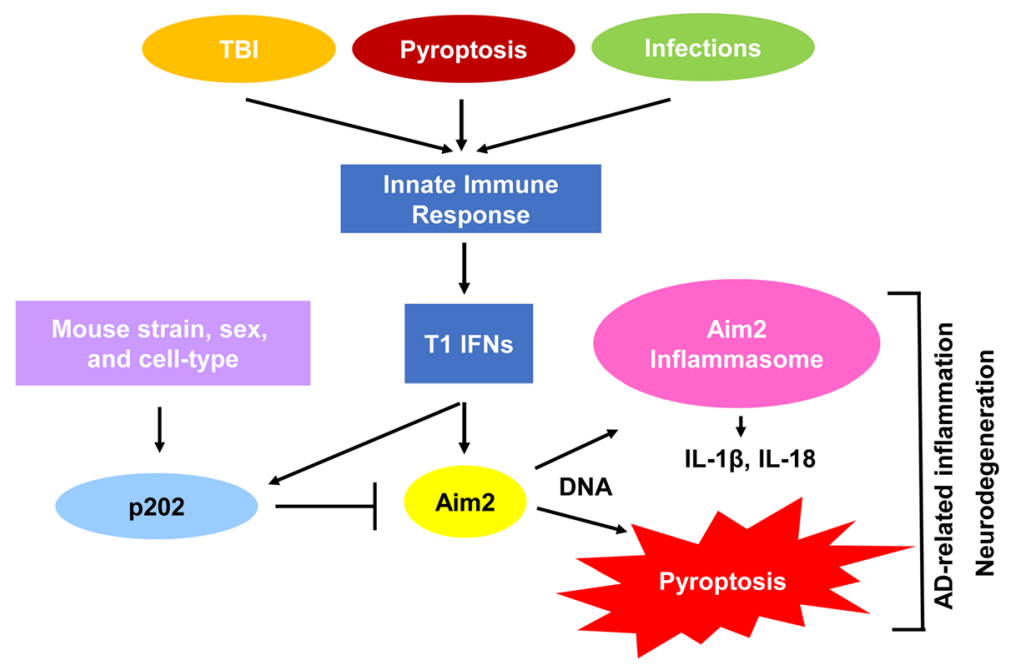

Fig. 2 Aim2 and p202 proteins in modulation of AD-related inflammation and neurodegeneration. TBI, pyroptosis, and brain infections activate innate immune responses in microglia through stimulation of TLRS and ISD pathway, resulting in the T1 IFN response and upregulation of the Aim2 and Ifi202 gene expression. A higher Aim2-to-p202 protein ratio in macrophages/microglia, which depends upon the genetic background of the mice, sex, and cell-type, is predicted to result in activation of the Aim2 inflammasome and pyroptosis, resulting in AD-related inflammation and neurodegeneration. However, a higher p202-to-Aim2 protein ratio in microglia is predicted to suppress AD-related inflammation and maintain homeostasis in the CNS

chemokines and cytokines (including IL-6 and CXCL1) [44]. Together, these observations support the idea that upregulation of the Aim2 gene expression in the CNS by T1 IFNs or by an infection by bacteria may contribute to neuroinflammation.

Cultured cortical and hippocampal mouse neurons expressed higher basal levels of Aim 2 mRNA and treatment of neurons with synthetic double-stranded DNA induced IL-1 $\beta$ secretion in Aim2-dependent manner [46]. Interestingly, activation of the Aim2 inflammasome in neurons and IL-1 $\beta$-induced signaling downregulated dendritic cell growth but enhanced axon extension. Further, a knockdown or knockout of the Aim2 gene expression in neurons indicated that Aim2 protein acted in cell-autonomous manner to regulate the neuronal morphology. Notably, the behavioral analyses of the Aim2 $2^{-1-}$.(B6.Sv129) mice revealed that the mice exhibited lower locomotor activity, increased anxious behaviors, and a reduced auditory fear memory [46]. However, it remains unclear whether the phenotype exhibited by the Aim2 ${ }^{-/-}$.(B6.Sv129) mice is due to activation of the T1 IFN response, which increases the expression of the p202 protein.

\section{Aim2 protein in traumatic brain and spinal cord injuries}

Using a controlled cortical impact (CCI) mouse model for traumatic brain injury (TBI) and manipulating the extent of pyroptosis in blood-brain barrier (BBB) cells, one study noted that TBI resulted in Aim2 inflammasome-mediated pyroptosis in brain microvascular endothelial cells (BMVECs) within injured cerebral cortex region [47]. Further, treatment with an inhibitor of caspase-1 (Ac-YVAD-cmk), which inhibited pyroptosis in the BMVECs and the release of pro-inflammatory cytokines (IL-1 $\beta$ and IL-18), decreased the TBI-induced blood-brain barrier leakage, brain edema, loss of tight junction proteins, and the inflammatory response in injured BMVECs. Correspondingly, the treatment also improved the neurological outcome of CCI in the mice. Similarly, using a rodent model of stroke, a study showed that Aim2 inflammasome activation contributes to brain injury [45]. Together, these observations may suggest a role for the Aim2 inflammasome activation in TBI and stroke-associated neuroinflammation.

In a rat model of T9 spinal cord contusive injury (SCI), levels of the Aim2 protein were measurably higher than sham-operated rats after $1 \mathrm{~h}, 6 \mathrm{~h}$, and 1 day of the injury [48]. Further, the basal expression of the Aim2 gene was detectable in neurons, astrocytes, oligodendrocytes, and microglia in the sham-operated spinal cord. In rats with SCI, Aim2 protein was also detectable in leukocytes and activated microglia/macrophages $\left(\mathrm{CD}^{+} 8^{+}\right.$ cells) in the spinal cord. These observations are consistent with the possibility that Aim2 protein is 
expressed in the normal spinal cord, and after SCI, expression of the Aim 2 gene increases in activated astrocytes and microglia due to the secretion of certain cytokines by infiltrated leukocytes.

\section{Aim2 in Alzheimer's disease}

Using the wild-type B6, Aim2 $2^{-/-}$.(B6.Sv129), 5XFAD, and Aim2 $2^{-1-}$.(B6.Sv129); 5XFAD mice, a study noted that Aim2 gene deficiency in the Aim2 ${ }^{-/-}$.(B6.Sv129); 5XFAD mice mitigated the $A \beta$ deposition in the cerebral cortex and hippocampus region as compared with the parental 5XFAD mice [23]. Further, activation of microglia was decreased in the brains of $A i m 2^{-/-}$.(B6.Sv129); 5XFAD mice as compared with age-matched 5XFAD mice. Surprisingly, the Aim2 ${ }^{-1-}$.(B6.Sv129) mice did not exhibit an improved memory and reduced anxiety as compared with 5XFAD mice in behavioral tests [23]. Compared with 5XFAD mice, IL-1 expression did not decrease in the Aim $^{-1-}$.(B6.Sv129); 5XFAD mice, thus suggesting a role for other inflammasomes in the observed phenotype. Of interest, IL-6 and IL-18 expression was higher in brains from the $\operatorname{Aim}^{-1-}(B 6$. Sv129); 5XFAD mice than the 5XFAD mice [23].

In another study [78], the APP/PS1 male mice (synonymous to the 5XFAD mice, age 6 months) exhibited increased levels of the Aim2 protein in the hippocampus (in particular, in the CA1 neurons). Further, Aim 2 gene deletion in APP/PS1 mice increased spatial memory in behavioral tests, facilitated the long-term potentiation in hippocampal slices, altered the structure of dendrites, and increased the dendritic spine densities. Notably, a transcriptional analysis revealed that Aim 2 gene deletion in the APP/PS1 mice altered the expression levels of certain proteins, including Pten, Homer1, and Ppp2r3a, and increased activation of the AKT protein kinase [78]. These observations are consistent with a role of the Aim2 inflammasome activation in neuroinflammation.

In Aim $^{-1-}$.(B6.Sv129); 5XFAD AD mouse model, the lack of Aim 2 protein function reduced $A \beta$ deposition in the brain [23]. Considering that Aim 2 gene deficiency in the mice is predicted to increase the expression of $\mathrm{T} 1$ IFN- $\beta$ and activate a T1 IFN response $[50,51]$ and activation of the T1 IFN response in microglia increased Trem 2 mRNA levels [79], which encodes for the TREM2 receptor that regulates microglial functions (including phagocytosis of $\mathrm{A} \beta$ deposits) [80], it is conceivable that the Aim2 gene deficiency reduced the $\mathrm{A} \beta$ deposits in the Aim2 ${ }^{-1-}$.(B6.Sv129); 5XFAD AD mouse model through upregulation of the Trem 2 gene expression. Therefore, it is important to determine the role of Aim 2 protein and its negative regulators in the regulation of $A \beta$ deposition.

In Aim $^{-/-}$.(B6.Sv129); 5XFAD mice, Aim2 gene deficiency increased the levels of certain pro-inflammatory cytokines (including IL-6) in the brain and had limited effect on the cognitive behavior of the mice. As noted above, Aim2 gene deficiency in the B6.Sv129 or B6 mice activated a T1 IFN response, resulting in an increase in the expression of p202 protein (encoded by the Ifi202 gene) $[50,51]$. The p202 protein is a transcriptional modulator, which can modulate the activities of the E2Fs, p53, NF-kB, and MyoD transcription factors [54]. Therefore, it is not surprising that the APP/PS1 mice deficient in the Aim2 gene exhibited the transcriptional changes in certain genes [78]

Interestingly, Aim 2 gene deficiency in the B6.Sv129 mice resulted in inflammation in white adipose tissue and associated with an increase in the expression of the Ifi202 gene [59]. Further, a knockdown of Ifi202 gene expression in stromal vascular fraction (SVF) inhibited adipogenesis and inflammation [59]. Additionally, bone marrow macrophages from the Aim2-deficient B6.Sv129 mice, upon challenge with LPS, expressed significantly higher levels of IL-6 mRNA [59]. Together, these observations support the hypothesis that Aim2 protein expression in 5XFAD or APP/PS1 AD mice suppresses neuroinflammation in part by suppressing the expression of certain T1 IFN-inducible proteins, including the p202 protein.

\section{Regulation of the ATM protein kinase by Aim2/ AIM2 proteins and neurodegeneration}

Neurodegeneration in ataxia telangiectasia (A-T) patients is caused by inheriting mutations in the ATM (A$\mathrm{T}$ mutated) gene $[81,82]$, which encodes for the ATM protein kinase. Notably, a defect in the ATM-signaling is noted in the neuronal death in individuals with $\mathrm{AD}$ [81]. Accordingly, hemizygous Atm-deficient mice and certain AD mouse models exhibited a loss of ATM protein kinase functions in neurons [83]. Interestingly, the loss of neurons in the brain correlated with the $\mathrm{AD}$ disease stage [84]. Further, the loss of ATM protein kinase function in microglia resulted in accumulation of cytosolic DNA, which activates the ISD pathway [85]. As noted above, activation of ISD pathway in macrophages/microglia upregulates the Aim2 protein expression, activation of the Aim2 inflammasome, and pyroptosis. Therefore, the above observations are consistent with functional interactions between ATM protein kinase and Aim2 protein in modulating neuroinflammation and neurodegeneration (Fig. 3).

The ATM protein kinase family also includes DNAdependent protein kinase (DNA-PK) [86]. Interestingly, binding of the Aim2 protein with the catalytic subunit of DNA-PK (DNA-PKc) inhibited its kinase activity and the DNA-PKc-mediated activation of the AKT protein kinase [87]. Further, a deficiency of the Aim2 gene in epithelial cells [88] and hippocampus of 


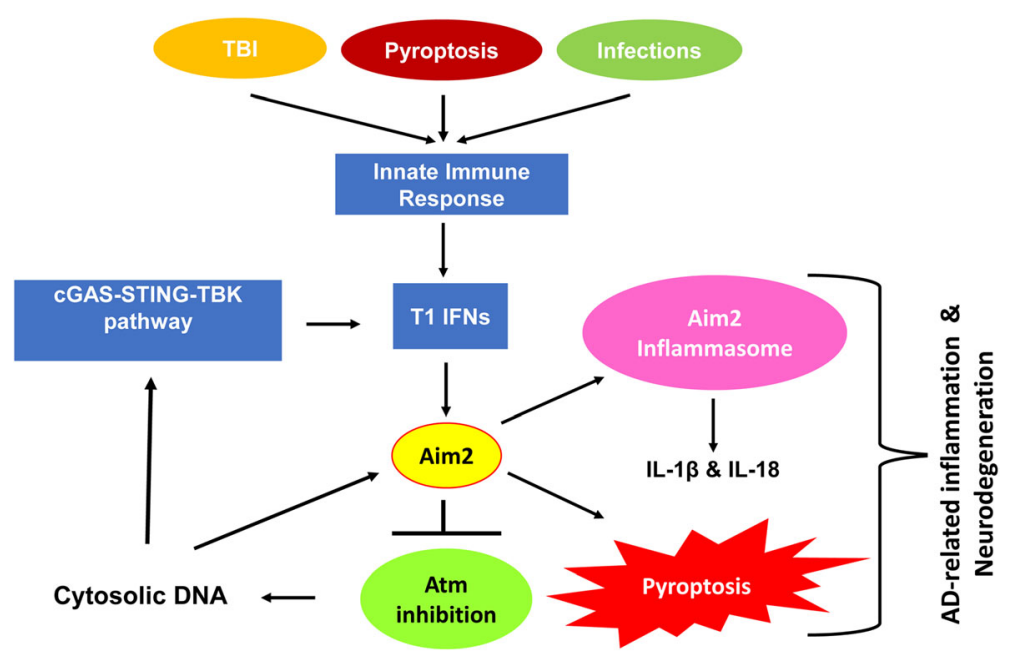

Fig. 3 The Atm-Aim2 axis in neuroinflammation and neurodegeneration. A knockdown of the AIM2 protein expression in human normal lung fibroblasts or a deficiency of the Aim2 gene in the murine bone marrow-derived macrophages activated ATM protein kinase (a member of the PI3-kinase/DNA-PK family, which can bind to Aim2 protein), thus suggesting a role for the Aim/AIM2 protein in inhibition of the ATM protein kinase activity. A dysfunction of ATM protein kinase in microglia accumulated DNA fragments in the cytoplasm, resulting in activation of the ISD pathway and T1 IFN response (the accumulation of cytosolic DNA did not result in activation of an inflammasome and pyroptosis). The T1 IFN response, which upregulates the expression of Aim2 protein, is predicted to "prime" microglia for activation of the Aim2/AIM2 inflammasome upon sensing higher levels of cytosolic DNA (due to TBI, pyroptosis, or infections), resulting in AD-related neuroinflammation, neurotoxicity, and neurodegeneration

the Aim2 $2^{-1-}$.(B6.Sv129) mice [78] activated the AKT protein kinase. Of interest, a knockdown of the AIM2 protein expression in human normal lung fibroblasts (WI-38), as compared with control WI-38 cells, activated ATM protein kinase [62]. Similarly, macrophages from the Aim2-deficient mice, as compared with age- and sex-matched wild-type B6 mice, exhibited activation of the ATM protein kinase [51]. Because defects in the ATM kinase activation are associated with activation of the T1 IFN response
[89] and activation of DNA-responsive inflammasome [90], studies are needed to assess the potential role of the Aim2/AIM2-ATM axis in modulating neuroinflammation and the development of AD.

\section{Conclusions}

Suppression of T1 IFN response by Aim2 and AIM2 proteins in the CNS may be important to keep the levels of the T1 IFN-inducible negative regulator proteins (murine p202 and human IFI16- $\beta$ and POP3) below a

Table 1 Murine Aim2 protein in neuroinflammation and neurodegeneration

\begin{tabular}{|c|c|c|c|}
\hline Animal model(s) & Aim2 expression/function & Phenotype/effect & Ref. \\
\hline ME7 prion, mouse & Aim2 expression upregulated & Neuroinflammation & {$[12]$} \\
\hline Aim2 $2^{-1-}$.B6.Sv129, mice & Aim2 gene deficient & $\begin{array}{l}\text { Lower locomotor activity, increased anxious behaviors, reduced fear } \\
\text { memory }\end{array}$ & [46] \\
\hline Aim2 $2^{-1-}$.B6.Sv129, mice & Aim2 gene deficient & $\begin{array}{l}\text { Increased inflammation and adipogenesis; increased expression of the } \\
\text { p202 protein }\end{array}$ & [59] \\
\hline $\begin{array}{l}\text { Traumatic brain injury, } \\
\text { mouse }\end{array}$ & Aim2 inflammasome activation & $\begin{array}{l}\text { Pyroptosis in brain microvascular endothelial cells, increased production } \\
\text { of neuroinflammatory cytokines }\end{array}$ & [47] \\
\hline Stroke, rat & Aim2 inflammasome activation & Production of neuroinflammatory cytokines & [45] \\
\hline $\begin{array}{l}\text { T9 spinal cord } \\
\text { contusive injury, rat }\end{array}$ & $\begin{array}{l}\text { Higher expression of Aim2 protein in } \\
\text { neurons and microglia }\end{array}$ & Neuroinflammation & [48] \\
\hline $\begin{array}{l}\text { Aim2 } 2^{-1-} \cdot \text { B6.Sv129; } \\
\text { 5XFAD, mice }\end{array}$ & Aim2 gene deficient & $\begin{array}{l}\text { Reduced amyloid- } \beta \text { deposition in brain, increased expression of IL- } 6 \text { and } \\
\text { IL-18 cytokines in the brain }\end{array}$ & [23] \\
\hline $\begin{array}{l}\text { Aim2 } 2^{-1-} \text {. B6.Sv129; APP/ } \\
\text { PS1, mice }\end{array}$ & Aim2 gene deficient & $\begin{array}{l}\text { Increased spatial memory, altered structure of dendrites, increased } \\
\text { dendritic spine densities }\end{array}$ & [78] \\
\hline
\end{tabular}


threshold to suppress neuroinflammation-related neurodegenerative diseases (Table 1). Notably, the generation of the Aim2-deficient 5XFAD AD mice on the pure B6 genetic background (Aim2.B6; 5XFAD) could provide novel insights into the precise role of the Aim2 protein in modulation of neuroinflammation and the development of AD. An improved understanding of the mechanisms by which Absent in Melanoma 2 proteins and their negative regulators modulate neuroinflammation could identify new approaches to treat AD.

\begin{abstract}
Abbreviations
AD: Alzheimer's disease; AIM2: Absent in Melanoma 2; ATM: Ataxia telangiectasia; BBB: Blood-brain barrier; CARD: Caspase recruitment domain; CGAS: Cyclic GMP-AMP synthase; CNS: Central nervous system; DNA-PK: DNAdependent protein kinase; IFN: Interferon; IFNAR: Interferon-a receptor; ISD: Interferon-stimulatory DNA; JAK: Janus kinase; IL-1: Interleukin 1; PBMCs: Peripheral blood mononuclear cells; POP3: Pyrin only protein; PYHIN: Pyrin and HIN domain containing interferon-inducible nuclear; STAT1: Signal transducer and activator of transcription-1; TBI: Traumatic brain injury
\end{abstract}

\section{Acknowledgements}

Not applicable

\section{Author's contributions}

DC wrote and edited this manuscript. The author read and approved the final manuscript.

\section{Funding}

Research work in the laboratory of the author has been supported by grants from the National Institutes of Health (USA) and VA Merit Awards from the US Department of Veterans Affairs.

\section{Availability of data and materials}

Not applicable

\section{Ethics approval and consent to participate}

Not applicable

\section{Consent for publication}

Not applicable

\section{Competing interests}

The author declares that he has no competing interests.

Received: 13 August 2019 Accepted: 11 November 2019

Published online: 26 November 2019

\section{References}

1. Schoggins JW, Rice CM. Interferon-stimulated genes and their antiviral effector functions. Curr Opin Virol. 2011;1(6):519-25.

2. Owens T, Khorooshi R, Wlodarczyk A, Asgari N. Interferons in the central nervous system: a few instruments play many tunes. Glia. 2014;62(3):339-55.

3. Blank T, Detje CN, Spieß A, Hagemeyer N, Brendecke SM, Wolfart J, et al. Brain endothelial- and epithelial-specific interferon receptor chain 1 drives virus-induced sickness behavior and cognitive impairment. Immunity. 2016; 44(4):901-12.

4. Wang J, Campbell IL, Zhang H. Systemic interferon-alpha regulates interferon-stimulated genes in the central nervous system. Mol Psychiatry. 2008;13(3):293-301.

5. Murray C, Griffin ÉW, O'Loughlin E, Lyons A, Sherwin E, Ahmed S, et al. Interdependent and independent roles of type I interferons and IL-6 in innate immune, neuroinflammatory and sickness behavior responses to systemic poly I:C. Brain Behav Immun. 2015;48:274-86.

6. Field R, Campion S, Warren C, Murray C, Cunningham C. Systemic challenge with the TLR3 agonist poly I:C induces amplified IFNalpha/beta and IL-1beta responses in the diseased brain and exacerbates chronic neurodegeneration. Brain Behav Immun. 2010 Aug;24(6):996-1007.

7. Khorooshi R, Owens T. Injury-induced type I IFN signaling regulates inflammatory responses in the central nervous system. J Immunol. 2010; 185(2):1258-64

8. Wang R, Yang B, Zhang D. Activation of interferon signaling pathways in spinal cord astrocytes from an ALS mouse model. Glia. 2011;59(6):946-58.

9. Hosmane S, Tegenge MA, Rajbhandari L, Uapinyoying P, Ganesh Kumar N, Thakor N, et al. Toll/interleukin-1 receptor domain-containing adapter inducing interferon- $\beta$ mediates microglial phagocytosis of degenerating axons. J Neurosci. 2012;32(22):7745-57.

10. Main BS, Zhang M, Brody KM, Ayton S, Frugier T, Steer D, et al. Type-1 interferons contribute to the neuroinflammatory response and disease progression of the MPTP mouse model of Parkinson's disease. Glia. 2016; 64(9):1590-604.

11. Minter MR, Moore Z, Zhang M, Brody KM, Jones NC, Shultz SR, et al Deletion of the type-1 interferon receptor in APPSWE/PS1 $\triangle$ E9 mice preserves cognitive function and alters glial phenotype. Acta Neuropathol Commun. 2016;4(1):72.

12. Cox DJ, Field RH, Williams DG, Baran M, Bowie AG, Cunningham C, et al. DNA sensors are expressed in astrocytes and microglia in vitro and are upregulated during gliosis in neurodegenerative disease. Glia. 2015;63(5):812-25.

13. Lin L, Hou J, Ma F, Wang P, Liu X, Li N, et al. Type I IFN inhibits innate IL-10 production in macrophages through histone deacetylase 11 by downregulating microRNA-145. J Immunol. 2013;191(7):3896-904.

14. Guarda G, Braun M, Staehli F, Tardivel A, Mattmann C, Förster I, et al. Type I interferon inhibits interleukin-1 production and inflammasome activation. Immunity. 2011;34(2):213-23.

15. Prinz M, Schmidt H, Mildner A, Knobeloch KP, Hanisch UK, Raasch J, et al. Distinct and nonredundant in vivo functions of IFNAR on myeloid cells limit autoimmunity in the central nervous system. Immunity. 2008;28(5):675-86.

16. Akwa Y, Hassett DE, Eloranta ML, Sandberg K, Masliah E, Powell H, et al. Transgenic expression of IFN-alpha in the central nervous system of mice protects against lethal neurotropic viral infection but induces inflammation and neurodegeneration. J Immunol. 1998;161(9):5016-26.

17. Campbell IL, Krucker T, Steffensen S, Akwa Y, Powell HC, Lane T, et al. Structural and functional neuropathology in transgenic mice with CNS expression of IFN-alpha. Brain Res. 1999;835(1):46-61.

18. Baruch K, Deczkowska A, David E, Castellano JM, Miller O, Kertser A, et al. Aging. Aging-induced type I interferon response at the choroid plexus negatively affects brain function. Science. 2014;346(6205):89-93.

19. Hwang SY, Hertzog PJ, Holland KA, Sumarsono SH, Tymms MJ, Hamilton JA, et al. A null mutation in the gene encoding a type I interferon receptor component eliminates antiproliferative and antiviral responses to interferons alpha and beta and alters macrophage responses. Proc Natl Acad Sci U S A. 1995;92(24):11284-8

20. Ejlerskov P, Hultberg JG, Wang J, Carlsson R, Ambjørn M, Kuss M, et al. Lack of neuronal IFN- $\beta$-IFNAR causes Lewy Body- and Parkinson's disease-like dementia. Cell. 2015;163(2):324-39.

21. Taylor JM, Minter MR, Newman AG, Zhang M, Adlard PA, Crack PJ. Type-1 interferon signaling mediates neuro-inflammatory events in models of Alzheimer's disease. Neurobiol Aging. 2014;35(5):1012-23.

22. Mesquita SD, Ferreira AC, Gao F, Coppola G, Geschwind DH, Sousa JC, et al. The choroid plexus transcriptome reveals changes in type I and II interferon responses in a mouse model of Alzheimer's disease. Brain Behav Immun. 2015:49:280-92.

23. Wu PJ, Hung YF, Liu HY, Hsueh YP. Deletion of the inflammasome sensor Aim2 mitigates $A \beta$ deposition and microglial activation but increases inflammatory cytokine expression in an Alzheimer disease mouse model. Neuroimmunomodulation. 2017:24(1):29-39.

24. Hofer MJ, Campbell IL. Type I interferon in neurological disease-the devil from within. Cytokine Growth Factor Rev. 2013:24(3):257-67.

25. Rodero MP, Crow YJ. Type I interferon-mediated monogenic autoinflammation: The type I interferonopathies, a conceptual overview. J Exp Med. 2016;213(12):2527-38

26. Lee-Kirsch MA. The type I interferonopathies. Annu Rev Med. 2017;68:297-315.

27. Sase S, Takanohashi A, Vanderver A, Almad A. Astrocytes, an active player in Aicardi-Goutières syndrome. Brain Pathol. 2018:28(3):399-407.

28. Cooper-Knock J, Kirby J, Ferraiuolo L, Heath PR, Rattray M, Shaw PJ. Gene expression profiling in human neurodegenerative disease. Nat Rev Neurol. 2012:8(9):518-30. 
29. Schwartz M, Deczkowska A. Neurological disease as a failure of brainimmune crosstalk: the multiple faces of neuroinflammation. Trends Immunol. 2016;37(10):668-79.

30. Saito T, Saido TC. Neuroinflammation in mouse models of Alzheimer's disease. Clin Exp Neuroimmunol. 2018;9(4):211-8.

31. Singhal G, Jaehne EJ, Corrigan F, Toben C, Baune BT. Inflammasomes in neuroinflammation and changes in brain function: a focused review. Front Neurosci. 2014;8:315.

32. Freeman LC, Ting JP. The pathogenic role of the inflammasome in neurodegenerative diseases. J Neurochem. 2016;136(Suppl 1):29-38.

33. Martinon F, Burns K, Tschopp J. The inflammasome: a molecular platform triggering activation of inflammatory caspases and processing of pro-ILbeta. Mol Cell. 2002 Aug;10(2):417-26.

34. Feng S, Fox D, Man SM. Mechanisms of gasdermin family members in inflammasome signaling and cell death. J Mol Biol. 2018:430(18 Pt B): 3068-80.

35. Halle A, Hornung V, Petzold GC, Stewart CR, Monks BG, et al. The NALP3 inflammasome is involved in the innate immune response to amyloid-beta. Nat Immunol. 2008:9(8):857-65.

36. Querfurth HW, LaFerla FM. Alzheimer's disease. N Engl J Med. 2010;362(4): 329-44.

37. McKenzie BA, Mamik MK, Saito LB, Boghozian R, Monaco MC, Major EO, et al. Caspase-1 inhibition prevents glial inflammasome activation and pyroptosis in models of multiple sclerosis. Proc Natl Acad Sci U S A. 2018; 115(26):E6065-74.

38. Shi Y, Holtzman DM. Interplay between innate immunity and Alzheimer disease: APOE and TREM2 in the spotlight. Nat Rev Immunol. 2018;18(12): 759-72.

39. Labzin LI, Heneka MT, Latz E. Innate immunity and neurodegeneration. Annu Rev Med. 2018 Jan 29:69:437-49.

40. Guillot-Sestier MV, Doty KR, Gate D, Rodriguez J Jr, Leung BP, Rezai-Zadeh K, et al. II10 deficiency rebalances innate immunity to mitigate Alzheimer-like pathology. Neuron. 2015;85(3):534-48

41. Michaud JP, Rivest S. Anti-inflammatory signaling in microglia exacerbates Alzheimer's disease-related pathology. Neuron. 2015;85(3):450-2.

42. McDonough A, Lee RV, Weinstein JR. Microglial interferon signaling and white matter. Neurochem Res. 2017;42(9):2625-38.

43. Adamczak SE, de Rivero Vaccari JP, Dale G, Brand FJ 3rd, Nonner D, Bullock $M R$, et al. Pyroptotic neuronal cell death mediated by the AIM2 inflammasome. J Cereb Blood Flow Metab. 2014:34(4):621-9.

44. Hanamsagar R, Aldrich A, Kielian T. Critical role for the AIM2 inflammasome during acute CNS bacterial infection. J Neurochem. 2014;129(4):704-11.

45. Denes A, Coutts G, Lénárt N, Cruickshank SM, Pelegrin P, Skinner J, et al. AIM2 and NLRC4 inflammasomes contribute with ASC to acute brain injury independently of NLRP3. Proc Natl Acad Sci U S A. 2015;112(13):4050-5.

46. Wu PJ, Liu HY, Huang TN, Hsueh YP. AIM 2 inflammasomes regulate neuronal morphology and influence anxiety and memory in mice. Sci Rep. 2016;6:32405.

47. Ge X, Li W, Huang S, Yin Z, Xu X, Chen F, et al. The pathological role of NLRs and AIM2 inflammasome-mediated pyroptosis in damaged bloodbrain barrier after traumatic brain injury. Brain Res. 1697:2018:10-20.

48. Wang SN, Guo XY, Tang J, Ding SQ, Shen L, Wang R, et al. Expression and localization of absent in melanoma 2 in the injured spinal cord. Neura Regen Res. 2019;14(3):542-52.

49. Panchanathan $R$, Duan X, Arumugam M, Shen $H$, Liu H, Choubey D. Cell type and gender-dependent differential regulation of the p202 and Aim2 proteins: implications for the regulation of innate immune responses in SLE. Mol Immunol. 2011;49(1-2):273-80.

50. Panchanathan $R$, Duan $X$, Shen $H$, Rathinam VA, Erickson LD, Fitzgerald KA, et al. Aim2 deficiency stimulates the expression of IFN-inducible Ifi202, a lupus susceptibility murine gene within the Nba2 autoimmune susceptibility locus. J Immunol. 2010:185(12):7385-93.

51. Choubey D, Panchanathan R. Absent in Melanoma 2 proteins in SLE. Clin Immunol. 2017:176:42-8.

52. Choubey D, Panchanathan R. Interferon (IFN)-inducible Absent in Melanoma 2 proteins in the negative regulation of the type I IFN response: Implications for lupus nephritis. Cytokine. 2019; pii: S1043-4666(19)30086-9 https://doi.org/10.1016/j.cyto.2019.03.008.

53. Brunette RL, Young JM, Whitley DG, Brodsky IE, Malik HS, Stetson DB. Extensive evolutionary and functional diversity among mammalian AIM2like receptors. J Exp Med. 2012;209(11):1969-83.
54. Choubey D. DNA-responsive inflammasomes and their regulators in autoimmunity. Clin Immunol. 2012 Mar;142(3):223-31.

55. Connolly DJ, Bowie AG. The emerging role of human PYHIN proteins in innate immunity: implications for health and disease. Biochem Pharmacol. 2014;92(3):405-14

56. Wang PH, Ye ZW, Deng JJ, Siu KL, Gao WW, Chaudhary V, et al. Inhibition of AIM2 inflammasome activation by a novel transcript isoform of IFI16. EMBO Rep. 2018; 19(10) https://doi.org/10.15252/embr.201845737. pii: e45737.

57. Yin Q, Sester DP, Tian Y, Hsiao YS, Lu A, Cridland JA, et al. Molecular mechanism for p202-mediated specific inhibition of AIM2 inflammasome activation. Cell Rep. 2013;4(2):327-39.

58. Khare S, Ratsimandresy RA, de Almeida L, Cuda CM, Rellick SL, Misharin AV, et al. The PYRIN domain-only protein POP3 inhibits ALR inflammasomes and regulates responses to infection with DNA viruses. Nat Immunol. 2014;15(4):343-53.

59. Gong Z, Zhang X, Su K, Jiang R, Sun Z, Chen W, et al. Deficiency in AIMZ induces inflammation and adipogenesis in white adipose tissue leading to obesity and insulin resistance. Diabetologia. 2019. https://doi.org/10.1007/ s00125-019-04983-x [Epub ahead of print]

60. Cridland JA, Curley EZ, Wykes MN, Schroder K, Sweet MJ, Roberts TL, et al. The mammalian PYHIN gene family: phylogeny, evolution and expression. BMC Evol Biol. 2012:12:140.

61. Wu X, Hakimi M, Wortmann M, Zhang J, Böckler D, Dihlmann S. Gene expression of inflammasome components in peripheral blood mononuclear cells (PBMC) of vascular patients increases with age. Immun Ageing. 2015;12:15.

62. Duan X, Ponomareva L, Veeranki S, Panchanathan R, Dickerson E, Choubey D. Differential roles for the interferon inducible IFI16 and AIM2 innate immune sensors for cytosolic DNA in cellular senescence of human fibroblasts. Mol Cancer Res. 2011:9(5):589-602.

63. Wang Q, Westra J, van der Geest KS, Moser J, Bijzet J, Kuiper T, Lorencetti PG, Joosten LA, Netea MG, Heeringa P, Brouwer E, Boots AM. Reduced levels of cytosolic DNA sensor AIM2 are associated with impaired cytokine responses in healthy elderly. Exp Gerontol. 2016;78:39-46.

64. Sweeney MD, Montagne A, Sagare AP, Nation DA, Schneider LS, Chui HC, et al. Vascular dysfunction-The disregarded partner of Alzheimer's disease. Alzheimers Dement. 2019;15(1):158-67.

65. Yang CA, Huang ST, Chiang BL. Sex-dependent differential activation of NLRP3 and AIM2 inflammasomes in SLE macrophages. Rheumatology (Oxford). 2015:54(2):324-31.

66. Panchanathan R, Shen H, Bupp MG, Gould KA, Choubey D. Female and male sex hormones differentially regulate expression of Ifi202, an interferoninducible lupus susceptibility gene within the Nba2 interval. J Immunol. 2009:183(11):7031-8.

67. Alimirah F, Chen J, Xin H, Choubey D. Androgen receptor auto-regulates its expression by a negative feedback loop through up-regulation of IFI16 protein. FEBS Lett. 2006;580(6):1659-64.

68. Lv W, Du N, Liu Y, Fan X, Wang Y, Jia X, et al. Low testosterone level and risk of Alzheimer's disease in the elderly men: a systematic review and meta-analysis. Mol Neurobiol. 2016;53(4):2679-84.

69. Jones JW, Kayagaki N, Broz P. Henry T, Newton K, O'Rourke K, et al. Absent in melanoma 2 is required for innate immune recognition of Francisella tularensis. Proc Natl Acad Sci U S A. 2010;107(21):9771-6.

70. Xiao TS, Fitzgerald KA. The cGAS-STING pathway for DNA sensing. Mol Cell. 2013:51(2):135-9.

71. Ablasser A, Chen ZJ. cGAS in action: expanding roles in immunity and inflammation. Science. 2019;363(6431). https://doi.org/10.1126/science. aat8657.

72. Lugrin J, Martinon F. The AIM2 inflammasome: sensor of pathogens and cellular perturbations. Immunol Rev. 2018;281(1):99-114.

73. Corrales L, Woo SR, Williams JB, McWhirter SM, Dubensky TW Jr, Gajewski TF. Antagonism of the STING pathway via activation of the AIM2 inflammasome by intracellular DNA. J Immunol. 2016;196(7):3191-8.

74. Rozzo SJ, Allard JD, Choubey D, Vyse TJ, Izui S, Peltz G, et al. Evidence for an interferon-inducible gene, Ifi202, in the susceptibility to systemic lupus. Immunity. 2001:15(3):435-43.

75. Nakaya Y, Lilue J, Stavrou S, Moran EA, Ross SR. AIM2-like receptors positively and negatively regulate the interferon response induced by cytosolic DNA. MBio. 2017;8(4) https://doi.org/10.1128/mBio.00944-17. pii: e00944-17.

76. Unterholzner L, Keating SE, Baran M, Horan KA, Jensen SB, Sharma S, et al. IFI16 is an innate immune sensor for intracellular DNA. Nat Immunol. 2010; 11(11):997-1004. 
77. Veeranki S, Duan X, Panchanathan R, Liu H, Choubey D. IFl16 protein mediates the anti-inflammatory actions of the type-l interferons through suppression of activation of caspase-1 by inflammasomes. PLoS One. 2011; 6(10):e27040.

78. Chen J, Shu S, Chen Y, Liu Z, Yu L, Yang L, et al. AlM2 deletion promotes neuroplasticity and spatial memory of mice. Brain Res Bull. 2019;152:85-94.

79. Nazmi A, Field RH, Griffin EW, Haugh O, Hennessy E, Cox D, et al. Chronic neuro-degeneration induces type I interferon synthesis via STING, shaping microglial phenotype and accelerating disease progression. Glia. 2019;67(7): 1254-76.

80. Konishi H, Kiyama H. Microglial TREM2/DAP12 signaling: a double-edged sword in neural diseases. Front Cell Neurosci. 2018;12:206.

81. Shiloh Y, Rotman G. Ataxia-telangiectasia and the ATM gene: linking neurodegeneration, immunodeficiency, and cancer to cell cycle checkpoints. J Clin Immunol. 1996;16(5):254-60.

82. McKinnon PJ. ATM and ataxia telangiectasia. EMBO Rep. 2004;5(8):772-6.

83. Kuljis RO, Xu Y, Aguila MC, Baltimore D. Degeneration of neurons, synapses, and neuropil and glial activation in a murine Atm knockout model of ataxia-telangiectasia. Proc Natl Acad Sci U S A. 1997;94(23):12688-93.

84. Oakley H, Cole SL, Logan S, Maus E, Shao P, Craft J, et al. Intraneuronal betaamyloid aggregates, neurodegeneration, and neuron loss in transgenic mice with five familial Alzheimer's disease mutations: potential factors in amyloid plaque formation. J Neurosci. 2006;26(40):10129-40.

85. Song X, Ma F, Herrup K. Accumulation of cytoplasmic DNA due to ATM deficiency activates the microglial viral response system with neurotoxic consequences. J Neurosci. 2019:39(32):6378-94.

86. Smith GC, Divecha N, Lakin ND, Jackson SP. DNA-dependent protein kinase and related proteins. Biochem Soc Symp. 1999;64:91-104.

87. Wilson JE, Petrucelli AS, Chen L, Koblansky AA, Truax AD, Oyama Y, et al. Inflammasome-independent role of AIM2 in suppressing colon tumorigenesis via DNA-PK and Akt. Nat Med. 2015;21(8):906-13.

88. Siddoo-Atwal C, Haas AL, Rosin MP. Elevation of interferon beta-inducible proteins in ataxia telangiectasia cells. Cancer Res. 1996;56(3):443-7.

89. Morales AJ, Carrero JA, Hung PJ, Tubbs AT, Andrews JM, Edelson BT, et al. A type I IFN-dependent DNA damage response regulates the genetic program and inflammasome activation in macrophages. Elife. 2017;6. pii: e24655.

90. Chen J, Wang Z, Yu S. AIM2 regulates viability and apoptosis in human colorectal cancer cells via the PI3K/Akt pathway. Onco Targets Ther. 2017;10; $811-7$.

\section{Publisher's Note}

Springer Nature remains neutral with regard to jurisdictional claims in published maps and institutional affiliations.

Ready to submit your research? Choose BMC and benefit from:

- fast, convenient online submission

- thorough peer review by experienced researchers in your field

- rapid publication on acceptance

- support for research data, including large and complex data types

- gold Open Access which fosters wider collaboration and increased citations

- maximum visibility for your research: over $100 \mathrm{M}$ website views per year

At BMC, research is always in progress.

Learn more biomedcentral.com/submissions 